\title{
Relatónio sobre a IV Jomada sobre Doenças Tropicais e I Encontro de Malária do Baixo Amazonas
}

\author{
AVALIAÇÃO DO PROGRAMA \\ ATUAL DE MALÁRIA
}

\section{ASSUNTO:}

\subsection{OPS (Dr. Carlos Catão)}

Abordando o combate a malária no Brasil mencionou como:

\section{Pontos positivos:}

a) erradicação na área extra-amazônica;

b) uso combinado da borrifação intradomiciliar e tratamento dos positivos;

c) estratégia de trabalho hierarquizado entre os servidores;

\section{Pontos negativos:}

a) tentativa de aplicar na área da Amazônia a mesma estratégia;

b) constatação da impossibilidade em conseguir a erradicação;

c) intervenções eventuais sem sustentabilidade.

As características geográficas, ecológicas, sociais, econômicas, epidemiológicas, entomológicas e resistência às drogas foram mencionadas como desafios ao programa de controle na Amazônia.

Entre 1986 e 1997, várias iniciativas foram adotadas: Operação Impacto, PCMAM, Programa de Controle Integrado, permitindo resultados modestos e expansão da rede de diagnostico e/ou tratamento. Não foi alcançada a intersetorialidade, o controle seletivo de vetores, o envolvimento dos estados, sustentabilidade das ações, acompanhamento e supervisão.

Para o período 2000 a 2001 está em andamento o Plano de Intensificação das ações de controle da malária em Municípios considerados prioritários.

\subsection{OMS (Dr. Renato Gusmão)}

Iniciou sua apresentação mostrando o distanciamento dos casos de malária na América e a redução da borrifação intradomiciliar com o DDT.
Mencionou que em 1990 o Brasil contribuiu com 53,5\% dos casos e que em 1999: 36.802 .000 habitantes estão na área de alto risco.

Como problemas e obstáculos à implantação da estratégia Global de Controle da Malária mencionou:

a) resistência Interistitucional às mudanças;

b) falta de Recursos Humanos capacitados;

c) ineficiência na aplicação das medidas de controle;

d) desestruturação dos Programas de controle.

Como destaque, apresentou a necessidade do entendimento sobre os custos para salvar uma vida por malária que no período 1989-1992 era de $U \$ 3,847$ e no período 1993-96 passou para U\$1,517.

Encerrou mencionando o papel que pode desempenhar o Roll Back Malária com a integração dos recursos, controle da transmissão com base nas ações coordenadas e simultâneas, implantação da política de antimaláricos e investigação técnica-operacional.

\subsection{FUNASA (Dr. Carlos Mangabeira)}

Apresentou os dados referentes aos casos de malária na Amazônia, destacando que em 1980 a participação dessa região era de $94,9 \%$ e em 1999 foi de 99,7\%. Também mencionou que no período 1970-1991 ocorreu um incremento populacional de $98,3 \%$, que guarda relação direta com a construção de rodovias, hidrelétricas e projetos de colonização.

Destacou que no período 1974-99 ocorreu crescimento da endemia com declínio no período 1994-96 e recrudescimento a partir de 1997. Também, que o P. falciparum hoje representa 18,6\% dos casos, embora no período de 1984-1988 tenha representado metade dos casos, conseqüentemente foi verificada até 1997 redução na letalidade por $P$. falciparum. Os últimos acontecimentos podem estar relacionados com a expansão da rede de diagnóstico que em 1989 era de 420 unidade e em 1997 estava com 1.300, com significativa participação do SUS. Fez referência ao reduzido número de casas borrifadas, chegando a $1 / 3$ do 
programado. Amazonas, Roraima e Pará no período 1991-1999 tiveram aumento importante da área de alto risco. Entre 1998 e 1999 na Amazônia, houve aumento da ordem de $39,3 \%$ dos casos de malária e em 2000, período jan-abril, a malária continua aumentando no Acre (AC), Roraima (RR), Amapá (AP) e Maranhão (MA).

\subsection{FUNASA (Dr. Romeo Fialho)}

Discutiu os aspectos relacionados as migrações para a Amazônia e suas relações com malária, descrevendo com bastante realidade a chegada dos migrantes em Rondônia na busca de trabalho, resultando em aumento da densidade populacional inicialmente na área rural e posteriormente nas periferias das cidades.

Quanto a borrifação intradomiciliar entende que deve ser realizada com cautela e não deve ser entendida como apanágio.

Citou alguns exemplos de atividades econômicas na Amazônia que se comportam como aumento na vulnerabilidade para transmissão da malária; os palmiteiros no Pará.

Identificou algumas dificuldades para implantação do PCIM: características epidemiológicas; financiamento das ações; insuficiente política de recursos humanos; ações não interinstitucionais e intersetoriais.

Finalizou mencionando a Portaria 1399/99 do Ministério da Saúde que trata da descentralização da Vigilância em Saúde e Controle de Endemias, e vários projetos ou Programas que podem de alguma forma contribuir para o Programa da Malária: Avança Brasil; PLANORTE; VIGISUS; Distritos Sanitários Indigenas; PACS/PSF; Aprimoramento do SISMAL; Findo Relatório da OMS; Roll Back Malária.

\section{DEBATEDORES/DISCUSSÃO}

\section{Assunto 1.1 e 1.2}

- Foi reforçada a necessidade de integração das medidas de controle com envolvimento do SUS.

- Para que os planos não continuem se comportando como bombeiros deve-se buscar sustentabilidade.

- Procurar uma forma de avaliação do consumo de drogas antimaláricas $x$ casos diagnosticados.

- Possibilitar o tratamento da malária de forma adequada nos locais onde está ocorrendo a transmissão.

- Avaliar o que significa aderência ou abandono no tratamento antimalárico quantitativamente e qualitativamente.

Assuntos 1.3 e 1.4

- No planejamento das ações de intervenção priorizou os fatores de riscos.

- Intensificar e valorizar a investigação científica.

- O SISMAL não permite com realidade o planejamento do controle seletivo de vetores.

- Monitorar emergência e Resistência dos plasmodios aos antimaláricos.

- Acompanhar as alterações (Modificações) no quadro clínico-laboratorial na malária vivax.

- As Universidades e Institutos devem ser mobilizados na intensificação do controle da malária.

- Considerar as relações entre os seres vivos e meio ambiente no planejamento das ações.

- De forma imperdoável ainda continuam ocorrendo óbitos por malária.

- Maior participação (com liberdade) dos Conselhos Municipais de Saúde, no tocante aos seus membros.

- As Ações do IEC devem, aparecer nas programações como realidade de execução.

\section{CARTA DE SANTARÉM}

A Comunidade Científica reunida em Santarém, no período de 23 a 29 do corrente, por ocasião da realização da IV Jornada sobre Doenças Tropicais e I Encontro de Malária do Baixo Amazonas, preocupada com a situação da malária no país, elaborou o relatório em anexo.

Os participantes desejam expressar sua aprovação ao Plano de Intensificação das Ações de Controle da Malária nos Estados da Amazônia
Legal, muito bem elaborado e já em vias de execução, acreditando que o mesmo poderá reverter a intolerável situação vigente na Amazônia em relação à malária.

Contudo, manifestam preocupação quanto a sua execução nos seguintes pontos:

1) Que os recursos financeiros alocados sejam transferidos em conformidade com a programação. 
2) Que os recursos financeiros sejam aplicados de acordo com os objetivos do Plano.

3) Que haja o imprescindivel acompanhamento, na execução do Plano, por Comissões Estaduais de Avaliação.
4) Que seja considerada a possibilidade de integração do Plano ao SUS, assegurando a sua sustentabilidade.

5) Que seja efetivada a contratação de Recursos Humanos estabelecidos no Plano.

Santarém, em 29 de julho de 2000 